\title{
Effects of captopril and a combination of hydralazine and isosorbide dinitrate on myocardial sympathetic tone in patients with severe congestive heart failure
}

\author{
PAUL DALY, JEAN-LUCIEN ROULEAU, DANIEL COUSINEAU, \\ JOHN H BURGESS, KANU CHATTERJEE*
}

From the Cardiovascular Division and the University Medical Clinics, Montreal General Hospital, McGill University, Montreal, Canada; and *Cardiovascular Division, Department of Medicine, University of California, San Francisco, California, USA

SUMMARY Changes in circulating catecholamines and transmyocardial catecholamine balance associated with improved left ventricular function were studied in patients with chronic heart failure after treatment with captopril (10 patients) and hydralazine in combination with isosorbide dinitrate (eight patients). Cardiac performance improved in response to both captopril and hydralazine-nitrate treatment. The systemic haemodynamic effects were also qualitatively similar, but the hydralazine-nitrate combination caused a greater increase in cardiac index and heart rate. Captopril did not change arterial adrenaline concentrations $(0.63$ to $0.60 \mathrm{nmol} / \mathrm{l})$, arterial noradrenaline ( 4.2 to $3.9 \mathrm{nmol} / 1)$, or net transmyocardial noradrenaline release (390 to $317 \mathrm{pmol} / \mathrm{min}$ ), while hydralazine-nitrate increased arterial adrenaline $(0.91$ to $1.47 \mathrm{nmol} / \mathrm{l})$ and transmyocardial noradrenaline release (225 to $554 \mathrm{pmol} / \mathrm{min}$ ).

Although both captopril and hydralazine-nitrate treatment improve left ventricular performance in patients with chronic heart failure, hydralazine-nitrate enhances cardiac sympathetic tone and captopril does not. The clinical relevance of these findings, however, is not known.

Captopril and the combination of hydralazine and isosorbide dinitrate are two vasodilator drug regimens which are frequently used to treat patients with congestive heart failure. ${ }^{12}$ They have significantly different systemic haemodynamic effects, but the mechanisms for these remain unclear. ${ }^{2-4} \mathrm{We}$ and others have postulated that these differences may be related to the different effects of these drugs on cardiac sympathetic tone. ${ }^{35}$

In patients with heart failure, captopril has been shown to reduce circulating noradrenaline concentrations, ${ }^{6}$ while the effects of hydralazine have been variable. ${ }^{78}$ In order to measure in vivo cardiac sympathetic activation it is necessary to measure not only

Requests for reprints to Dr Jean-Lucien Rouleau, Research Center, Hôpital du Sacre-Coeur, 5400 Gouin Boulevard West, Montreal, Quebec, Canada H4J 1 C5.

Accepted for publication 14 April 1986 arterial adrenaline and noradrenaline concentrations but also cardiac catecholamine balance. ${ }^{9}$

We administered captopril or a combination of hydralazine and isosorbide dinitrate to 18 patients with congestive heart failure associated with coronary artery disease. We measured arterial adrenaline, arterial noradrenaline, and transmyocardial catecholamine balance before and after these interventions. Changes in systemic and coronary haemodynamic function were also assessed concurrently.

\section{Patients and methods}

Twenty one consecutive patients (16 male and five female) with chronic congestive heart failure associated with coronary artery disease who did not respond to digoxin and diuretic treatment were screened for this study. Three patients were 
excluded-two because of hypertension (mean arterial pressure of 136 and $138 \mathrm{~mm} \mathrm{Hg}$ ), and one patient because of a stroke work index $>35 \mathrm{~g} \mathrm{~m} / \mathrm{m}^{2}$. The remaining 18 patients enrolled in the study were 46-83 years old and had not experienced an acute ischaemic event for at least three months. In eight of the 18 patients coronary artery disease had been proved by selective coronary arteriography. The other 10 patients had at least one well documented myocardial infarction. Vasodilators were discontinued for 72 hours and all diuretics were discontinued for 24 hours before the start of the study. Digoxin was discontinued for 12 hours before the study.

\section{HAEMODYNAMIC STUDY}

Each patient gave informed written consent. The right heart catheterisation was performed with a flow directed balloon tip, and a number 7 Swan-Ganz thermodilution catheter was inserted percutaneously through the right subclavian vein to record right atrial pressure (RAP), pulmonary arterial pressure (PAP), and pulmonary capillary wedge pressure (PCWP). We used the same catheter to measure cardiac output $(\mathrm{CO})$ in triplicate by the thermodilution technique.

Arterial pressure was recorded directly by cannulating the radial artery. The haemodynamic variables were calculated as follows: SVI $\left(\mathrm{ml} /\right.$ beat $\left./ \mathrm{m}^{2}\right)=$ $\mathrm{CO} / \mathrm{HR} / \mathrm{BSA}$, where SVI is stroke volume index, HR is heart rate, and BSA is body surface area; SWI $\left(\mathrm{g} \mathrm{m} / \mathrm{m}^{2}\right)=$ SVI $\times($ MAP - PCWP $) \times 0.0136$, where SWI is stroke work index, SVI is stroke volume index, MAP is mean arterial pressure, and PCWP is pulmonary capillary wedge pressure; SVR $\left(\right.$ dyn.s. $\left.\mathrm{cm}^{-5}\right)=($ MAP - RAP $) / \mathrm{CO} \times 80$, where SVR is systemic vascular resistance.

Under fluoroscopic guidance, a number 8 thermodilution coronary sinus flow catheter was placed in the coronary sinus through the left subclavian vein. To minimise the coronary sinus reflux ${ }^{10}$ the catheter was advanced under fluoroscopy into the midcoronary sinus. Coronary sinus flow was measured by the constant infusion thermodilution technique. ${ }^{11-13}$ Coronary sinus flow in $\mathrm{ml} / \mathrm{min}$ was calculated as $[(\mathrm{Tb}-\mathrm{Ti} / \mathrm{Tb}-\mathrm{Tm})]-1 \times 1.08 \times 46$ $\mathrm{ml} / \mathrm{min}$, where $\mathrm{Tb}$ is temperature of blood; $\mathrm{Ti}$ is temperature of injectate; $\mathrm{Tm}$ is temperature of mixture of blood and the injectate; 1.08 is a constant accounting for specific heart and density of both blood and indicator; and $46 \mathrm{ml} / \mathrm{min}$ is the injection rate of the indicator $(5 \%$ dextrose in water) through the Harvard constant infusion pump.

Arterial and coronary sinus blood samples were drawn simultaneously for the determination of oxygen saturation, oxygen content, and lactate, adrenaline, and noradrenaline concentrations. Oxygen saturations were measured in duplicate by a Corning $158 \mathrm{pH}$ and blood gas analyser. Lactate concentrations were measured by the enzymatic fluorometric method of Loomis, ${ }^{14}$ adrenaline and noradrenaline concentrations were measured by the radioenzymatic assay of Peuler and Johnson, ${ }^{15}$ and the renin concentrations were measured by the New England Nuclear Radioimmunoassay.

Oxygen content was calculated as oxygen saturation $\times$ haemoglobin $\times 1.34$ and expressed in volume per cent. The arterial - coronary sinus oxygen difference (myocardial oxygen extraction) (ART $\mathrm{CS} \mathrm{DO}_{2}$ ) was calculated as arterial oxygen content (ART $\mathrm{O}_{2}$ ) - coronary sinus oxygen content (CS $\left.\mathrm{O}_{2}\right)$. Myocardial oxygen consumption $\left(\mathrm{MVO}_{2}\right)$ was calculated as (ART - CS DO 2$) \times \mathrm{CSF}(\mathrm{ml} / \mathrm{min}) \times$ 10 , and is expressed as $\mathrm{ml}$ of $\mathrm{O}_{2}$ per min, where CSF is coronary sinus flow. Myocardial lactate extraction was calculated as (ART lactate - CS lactate)/(ART lactate) $\times 100$, where ART lactate is arterial lactate concentration $(\mathrm{mg} / 100 \mathrm{ml}$ ) and CS lactate is coronary sinus lactate concentrations. Transmyocardial noradrenaline values $(\mathrm{pmol} / \mathrm{min})$ were calculated as (coronary sinus noradrenaline - arterial noradrenaline $) \times$ coronary sinus blood flow $(\mathrm{ml} / \mathrm{min})$.

\section{DRUG DOSAGE}

Once the catheters were inserted, the first 10 patients received captopril in increasing doses $(6 \cdot 25,12 \cdot 5,25$,

Table 1 Changes in systemic haemodynamic function (mean (SD))

\begin{tabular}{|c|c|c|c|c|c|c|c|}
\hline & $\begin{array}{l}\text { Heart } \\
\text { rate } \\
\text { (beats/min) }\end{array}$ & $\begin{array}{l}\text { Mean } \\
\text { blood } \\
\text { pressure } \\
(\mathrm{mm} \mathrm{Hg})\end{array}$ & $\begin{array}{l}\text { Diastolic } \\
\text { blood } \\
\text { pressure } \\
\text { ( } \mathrm{mm} \mathrm{Hg})\end{array}$ & $\begin{array}{l}P C W P \\
(m m H g)\end{array}$ & $\begin{array}{l}\text { Cardiac } \\
\text { index } \\
\left(l / \min / m^{2}\right)\end{array}$ & $\begin{array}{l}\text { Stroke } \\
\text { work } \\
\text { index } \\
\left(\mathrm{g} \cdot \mathrm{m} / \mathrm{m}^{2}\right)\end{array}$ & $\begin{array}{l}S V R \\
\left(d y n \cdot s \cdot \mathrm{cm}^{-5}\right)\end{array}$ \\
\hline \multicolumn{8}{|l|}{ Captopril: } \\
\hline Baseline & 94 (18) & $92(6)$ & $72(6)$ & 26 (11) & $2 \cdot 1(0.8)$ & $21(8)$ & $1913(627)$ \\
\hline \multicolumn{7}{|l|}{ Hydralazine + } & $1459(470) \dagger$ \\
\hline isosorbide nitrate: & & & & & & & \\
\hline $\begin{array}{l}\text { Baseline } \\
\text { Peak }\end{array}$ & $\begin{array}{l}100(11) \\
107(12)^{\star}\end{array}$ & $\begin{array}{l}93(16) \\
77(15) \dagger\end{array}$ & $\begin{array}{l}71(5) \\
57(12)^{\star}\end{array}$ & $\begin{array}{l}27(6) \\
21(10)^{\star}\end{array}$ & $\begin{array}{l}1.8(0.3) \\
2.5(0.3) \dagger\end{array}$ & $\begin{array}{l}17(9) \\
17(5)\end{array}$ & $\begin{array}{l}2031(470) \\
1273(505)^{\star}\end{array}$ \\
\hline
\end{tabular}

${ }_{\mathrm{p}}<0.05$ vs control; tp $<0.01$ vs control.

PCWP, pulmonary capillary wedge pressure; SVR, systemic vascular resistance. 
$50,100,150$, and $200 \mathrm{mg}$ ) every hour (mean $180 \mathrm{mg}$, but seven of 10 patients responded at doses < $100 \mathrm{mg}$ ) until there was a $>10 \mathrm{~mm} \mathrm{Hg}$ decrease in mean arterial pressure, or the second dose of $200 \mathrm{mg}$ of captopril was given. ${ }^{3}$ At this time a complete set of measurements was repeated. The next eight patients received a single $100 \mathrm{mg}$ dose of hydralazine and, $90 \mathrm{~min}$ later, received $30 \mathrm{mg}$ of oral isosorbide dinitrate. After another $30 \mathrm{~min}(120 \mathrm{~min}$ after the original hydralazine dose) a complete set of measurements was repeated. ${ }^{3}$

\section{STATISTICAL ANALYSIS}

The effect of a vasodilator in any given patient was compared with baseline values by a two tailed paired $t$ test. The change in any given variable caused by captopril was compared with that caused by the hydralazine-nitrate combination by a two tailed,

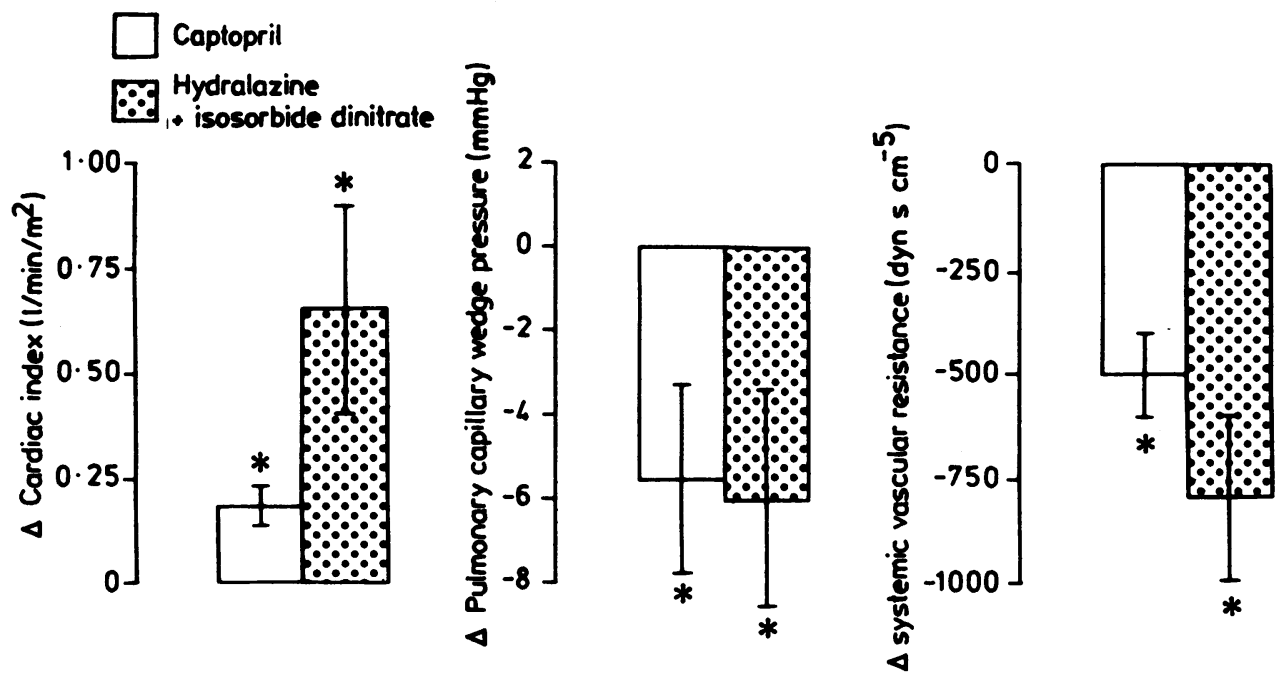

Fig 1 Systemic haemodynamic effects of captopril and hydralazine + isosorbide dinitrate in patients with severe congestive heart failure. Cardiac index increased in both groups of patients but the magnitude of increase was significantly greater in patients treated with hydralazine + isosorbide dinitrate. In both groups pulmonary capillary wedge pressure and systemic vascular resistance decreased to a similar extent. $\triangle$, change from control; ${ }^{\star} p<0.05$ vs control. Values are mean $(S E)$.

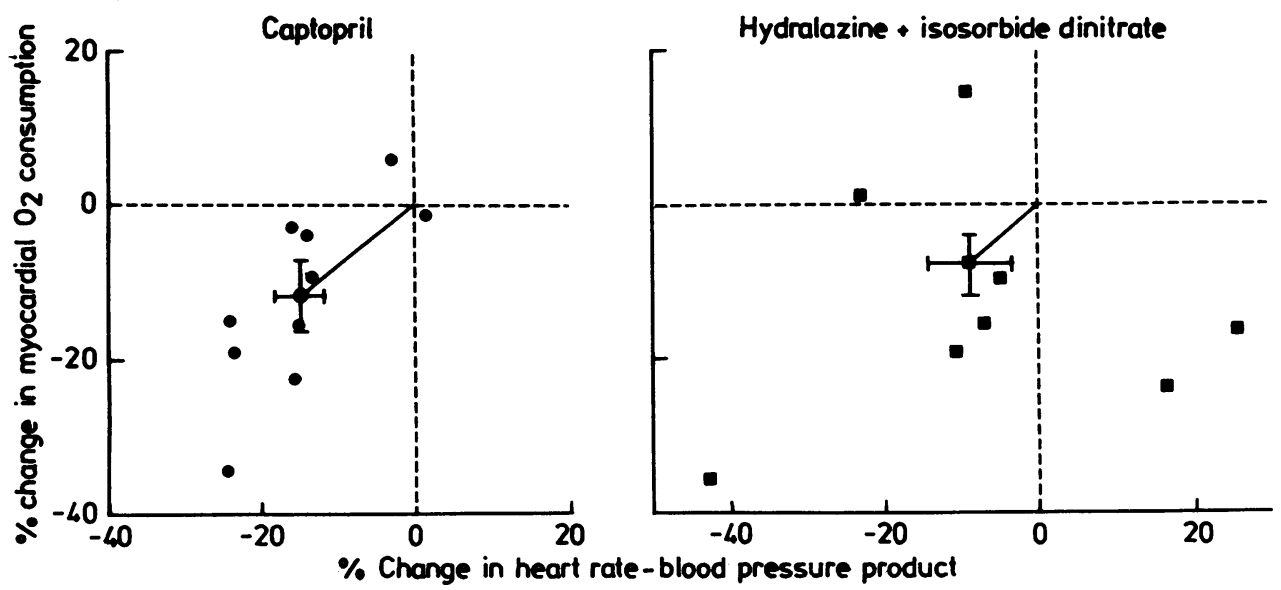

Fig 2 Relation between the percentage change in rate-pressure product and percentage change in myocardial oxygen consumption with captopril and with hydralazine + isosorbide dinitrate. The decrease in myocardial oxygen consumption with captopril parallels the decrease in the rate-pressure product, $r=0.81$, whereas this relation varies with hydralazine + isosorbide dinitrate. Values for mean (SE) are shown. 
Table 2 Changes in coronary haemodynamic function (mean (SD))

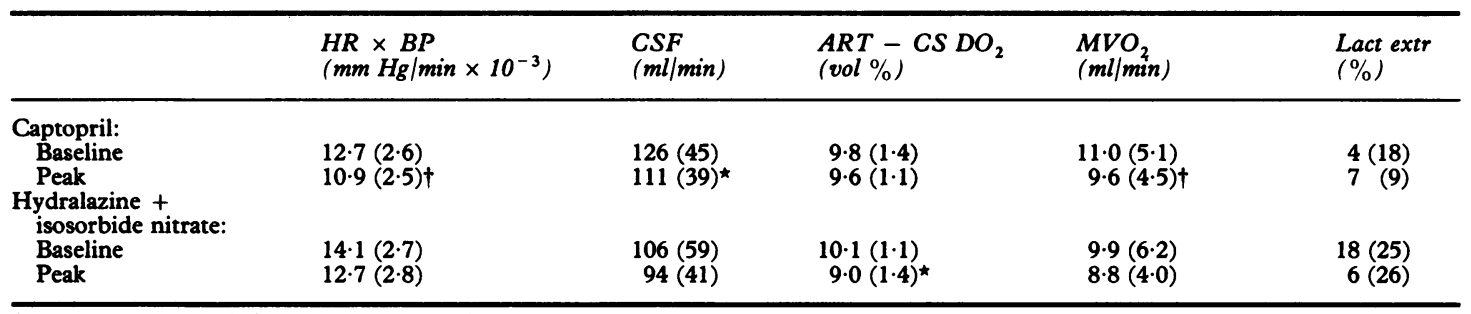

$\star \mathrm{p}<0.05$ vs control; tp $<0.01$ vs control.

$\mathrm{HR} \times \mathrm{BP}$, rate-pressure product; CSF, coronary sinus blood flow; ART $-\mathrm{CS} \mathrm{DO}_{2}$, myocardial oxygen extraction; $\mathrm{MVO}{ }_{2}$, myocardial oxygen consumption; Lact extr, myocardial lactate extraction.

Table 3 Changes in myocardial sympathetic tone (mean (SD))

\begin{tabular}{llll}
\hline & $\begin{array}{l}\text { Arterial noradrenaline } \\
(\text { nmol } / l)\end{array}$ & $\begin{array}{l}\text { Coronary sinus noradrenaline } \\
(\text { nmol } / l)\end{array}$ & $\begin{array}{l}\text { Transmyocardial noradrenaline } \\
(\text { pmol/min })\end{array}$ \\
\hline $\begin{array}{l}\text { Captopril: } \\
\text { Baseline }\end{array}$ & $\begin{array}{l}\text { Arterial } \\
\text { adrenaline } \\
(\text { nmol } / l)\end{array}$ \\
$\begin{array}{l}\text { Drug } \\
\text { Hydralazine }+\end{array}$ & $4.2(3.1)$ & $7.0(4.6)$ & $390(593)$ \\
isosorbide dinitrate: & $3.9(1.9)$ & $6.3(3.6)$ & $317(415)$ \\
$\begin{array}{l}\text { Baseline } \\
\text { Drug }\end{array}$ & $6.7(5.7)$ & $0.63(0.65)$ & $0.60(0.34)$ \\
\hline
\end{tabular}

${ }^{\star} \mathrm{p}<0.05 ;$ tp $<0.01$.

unpaired $t$ test. All values are mean (SD) unless otherwise specified.

\section{Results}

SYSTEMIC HAEMODYNAMIC FUNCTION

Baseline systemic haemodynamic function in both
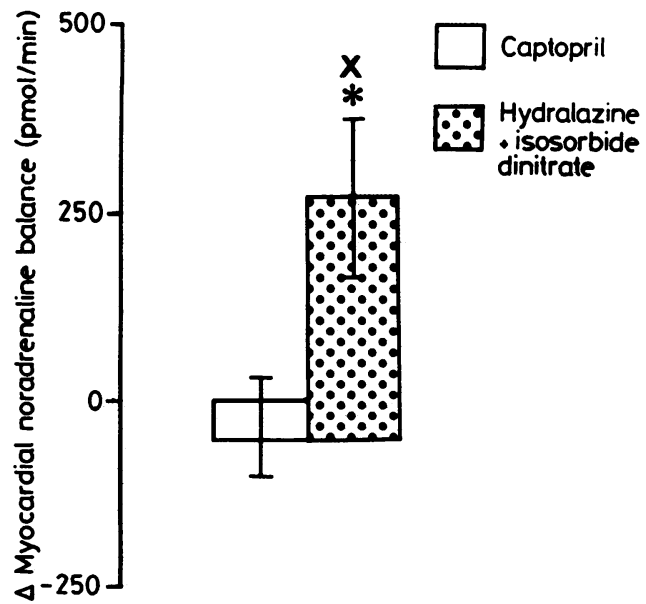

Fig 3 Effects of captopril and hydralazine + isosorbide dinitrate on net cardiac noradrenaline balance. There was no change in cardiac noradrenaline release with captopril, whereas hydralazine + isosorbide dinitrate increased net myocardial noradrenaline release compared with control or captopril. Myocardial noradrenaline balance = coronary sinus - arterial noradrenaline concentration $\times$ coronary sinus flow. Values for mean (SE) are shown. ${ }^{\star} p<0.05$ vs control, $\times p<0.05$ vs captopril. groups was similar (table 1). Captopril and the hydralazine-nitrate decreased systemic arterial pressure and pulmonary capillary wedge pressure to a similar extent; however, hydralazine-nitrate caused a larger increase in cardiac index and stroke volume index than did captopril (table 1, fig 1). Only hydralazine-nitrate caused a statistically significant increase in heart rate.

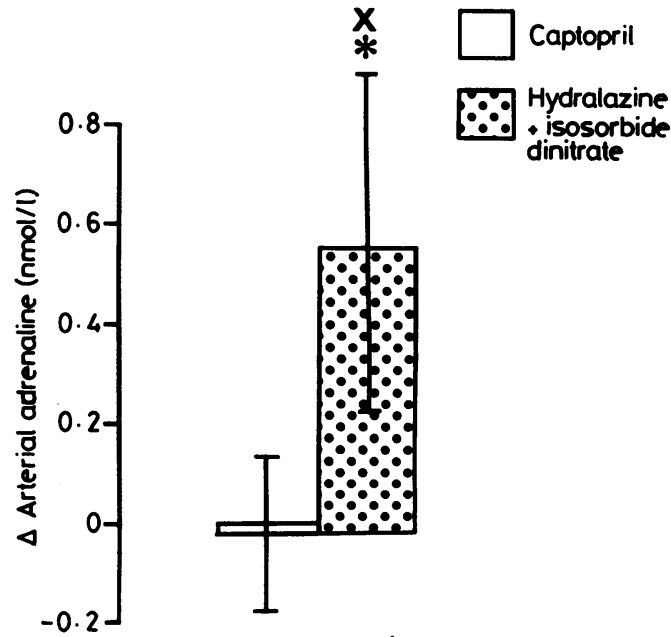

Fig 4 Change in arterial adrenaline concentration with captopril and hydralazine + isosorbide dinitrate.

Hydralazine + isosorbide dinitrate increased arterial adrenaline whereas captopril had no effect. ${ }^{\star} p<0.05$ vs control, $\times p<0.05$ vs captopril. 
CORONARY HAEMODYNAMIC FUNCTION

Captopril reduced the rate-pressure product, coronary sinus blood flow, and global myocardial oxygen consumption (table 2, fig 2). Hydralazine-nitrate also tended to decrease the rate-pressure product, coronary sinus flow, and average myocardial oxygen consumption, but the changes were variable (table 2 , fig 2) and not statistically significant ( $p>0 \cdot 1)$. Global myocardial lactate extraction did not change in either group.

MYOCARDIAL SYMPATHETIC ACTIVATION Captopril had no effect on arterial catecholamines or on transmyocardial catecholamine balance, whereas the combination of hydralazine-nitrate increased both arterial adrenaline and net transmyocardial noradrenaline release (table 3, figs 3 and 4 ). The increase in transmyocardial noradrenaline release with the combination of hydralazine and isosorbide dinitrate was primarily due to an increase in coronary sinus noradrenaline concentrations.

\section{Discussion}

This study confirms the differences in the short term systemic and coronary haemodynamic effects of captopril and the combination of hydralazine-isosorbide dinitrate in patients with chronic heart failure. ${ }^{12}$ Hydralazine-nitrate increases heart rate and cardiac index more than captopril does. With captopril the rate-pressure product fell consistently and myocardial oxygen requirements were reduced. There was a predictable decrease in myocardial oxygen consumption. With hydralazine-nitrate, ${ }^{23}$ however, no such relation was observed. The precise mechanism for these differences remains unclear; however, a reflex increase in myocardial sympathetic activation with hydralazine-nitrate that was not seen with captopril may provide a possible explanation.

This study demonstrated considerable differences in the short term effects of hydralazine-nitrates and captopril on circulating catecholamines and on transmyocardial catecholamine balance. With hydralazine-nitrate, arterial adrenaline increased and there was also a tendency for noradrenaline concentrations to be higher. Furthermore, the net transmyocardial release of noradrenaline increased in response to hydralazine-nitrate. With captopril, although the changes in circulating catecholamines and in transmyocardial catecholamine balance were not statistically significant, there was a tendency to lower arterial noradrenaline concentrations and decreased net transmyocardial noradrenaline release.

Because neither hydralazine nor isosorbide dinitrate has any direct effect on the sympathetic system, ${ }^{16-18}$ it is probable that the difference between these two regimens is the result of a direct neurohumoral effect of captopril on the sympathetic system. ${ }^{19-21}$ Converting enzyme inhibition reduces sympathetic activity in heart failure by attenuating the effects of angiotensin. Both hydralazine-nitrate and captopril reduced systemic arterial pressure; thus reflex activation of the sympathetic system should occur in response to both. It is likely, therefore, that captopril exerted a deactivating balancing influence on the sympathetic system, which probably resulted from its direct neurohumoral effect. With hydralazine-nitrate, reflex sympathetic activation remained unopposed. The observed differences in systemic and cardiac sympathetic activity in response to hydralazine-nitrate and captopril may have clinical relevance. The increase in heart rate and greater increase in stroke volume after hydralazine-nitrate may result from the reflex increase in sympathetic tone and contractility.

It has been suggested that an increase in the activity of circulating noradrenaline is associated with worse prognosis. ${ }^{22}$ It is possible, therefore, that the increase in cardiac sympathetic tone caused by the hydralazine-nitrate might have deleterious effects. Furthermore, an increase in sympathetic tone may activate the renin-angiotensin-aldosterone system and thus promote salt and water retention.

The mechanism by which captopril prevents cardiac sympathetic activation remains speculative; it is probably the result of attenuation of angiotensin II activity. Angiotensin II enhances sympathetic tone by central and peripheral mechanisms, ${ }^{19-21}$ and angiotensin II converting enzyme inhibitors have been shown to decrease hypoxia mediated noradrenaline release ${ }^{23}$ and to decrease the circulating catecholamines in hypertensive patients. ${ }^{24}$

This study has several limitations. First of all, these measurements were done with the patient in the supine position and there may be important differences between measurements taken while the patient is lying or standing. ${ }^{25}$ Second, coronary sinus blood flow determinations do not allow assessment of changes in regional blood flow, and important differences in perfusion are likely to occur in the presence of coronary artery disease. Nevertheless, this study shows that there are important differences between the effects of captopril and hydralazine-nitrate on cardiac sympathetic tone, despite their similar haemodynamic effects. Further studies will be required to evaluate the clinical relevance of these findings.

This work was supported by the Department of Medicine of the Montreal General Hospital, the Quebec Heart Foundation, and Medical Research Council of Canada, and a grant from the Don and 
Susan Schleicher Fund at the University of California, San Francisco.

\section{References}

1 Chatterjee K, Parmley WW. The role of vasodilator therapy in heart failure. Prog Cardiovasc Dis 1977;19:301-25.

2 Packer M, Meller J, Medina N, Yushak M, Gorlin R. Physiologic and pharmacologic determinants of vasodilator response: a conceptual framework for rational drug therapy for chronic heart failure. Prog Cardiovasc Dis 1982;24:275-92.

3 Rouleau JL, Chatterjee K, Benge W, Parmley WW, Hiramatsu B. Alterations in left ventricular function and coronary hemodynamics with captopril, hydralazine, and prazosin in chronic ischemic heart failure: a comparative study. Circulation 1982;65: 671-8.

4 Rouleau JL, Chatterjee K, Hiramatsu B, Parmley WW. Comparative hemodynamic effects on captopril, prazosin and hydralazine in congestive heart failure [Abstract]. Clin Res 1981;29:79A.

5 Packer M, Medina N, Yushak M, Meller J. Hemodynamic patterns of response during long-term captopril therapy for severe chronic heart failure. Circulation 1983;68:803-12.

6 Cody RJ, Franklin RW, Kluger J, Laragh JH. Sympathetic responsiveness and plasma norepinephrine during therapy of chronic congestive heart failure with captopril. Am f Med 1982;72:791-7.

7 Cohn JN, Taylor N, Urobel T, Moskowitz R. Contrasting effects of vasodilators on heart rate and plasma catecholamines in patients with hypertension and heart failure [Abstract]. Clin Res 1978;26:547A.

8 Markham RV, Gilmore A, Pettinger WA, Brater OC, Corbett JR, Firth BG. Control and regional hemodynamic effects and neurohormonal consequences of minoxidil in severe congestive heart failure and comparison to hydralazine and nitroprusside. Am $\mathfrak{f} \mathrm{Car}$ diol 1983;52:774-81.

9 Yamaguchi N, de Champlain J, Nadeau R. Correlation between the response of the heart to sympathetic stimulation and the release of endogenous catecholamines into the coronary sinus of the dog. Circ Res 1975;36:662-8.

10 Mathey DG, Chatterjee K, Tyberg JV, Lekven J, Brundage B, Parmley WW. Coronary sinus reflux: a source of error in the measurement of thermodilution coronary sinus flow. Circulation 1978;57:778-96.
11 Ganz W, Tamura K, Marcus HS, Donoso R, Yoshida S, Swan HJC. Measurement of coronary sinus blood flow by continuous thermodilution in man. Circulation 1971;46:181-95.

12 Lepine CJ, Mehta J, Webster WW Jr, Nicholls WW. In vivo validation of a thermodilution method to determine regional left ventricular blood flow in patients with coronary artery disease. Circulation 1978;58: 795-802.

13 Klocke PS. Coronary blood flow in man. Prog Cardiovasc Dis 1976;19:117-66.

14 Loomis ME. An enzymatic flurometric method for the determination of lactic acid in serum. $f$ Lab Clin Med 1961;57:966-9.

15 Peuler JD, Johnson GA. Simultaneous single isotope radioenzymatic assay of plasma norepinephrine, epinephrine and dopamine. Life Sci 1977;21:625-36.

16 Ablad B. A study of the mechanism of the hemodynamic effects of hydralazine in man. Acta Pharmacol Toxicol (Copenh) 1963;20 (suppl I):I-53.

17 Koch-Weser J. Vasodilator drugs in the treatment of hypertension. Arch Intern Med 1974;133:1017-27.

18 Leier CV, Desch CE, Magorien RD, et al. Positive inotropic effects of hydralazine in human subjects: comparison with prazosin in the setting of congestive heart failure. Am f Cardiol 1980;46:1039-44.

19 Reit E. Interaction of angiotensin with the autonomic nervous system. Fed Proc 1972;31:1331-64.

20 Berecek KH, Webb RL, Brody MJ. Evidence for a central role for vasopressin in cardiovascular regulation. Am F Physiol 1983;13:H-852-9.

21 McAubbin JW. Peripheral effects of angiotensin on the autonomic nervous system. In: Page IH, Bumpus FM, eds. Angiotensin handbook of experimental pharmacology. Vol. 37. New York: Springer-Verlag, 1979:417-23.

22 Cohn JN, Levine B, Olivari MT, et al. Plasma norepinephrine as a guide to prognosis in patients with chronic congestive heart failure. $N$ Engl $\mathfrak{f}$ Med 1984;311:819-23.

23 Liang CS, Gavras H. Renin-angiotensin system inhibition in conscious dogs during acute hypoxemia. f Clin Invest 1978;62:961-71.

24 Weinberger $\mathrm{MH}$. Role of sympathetic nervous system activity in the blood pressure response to long-term captopril therapy in severely hypertensive patients. Am $\mathcal{f}$ Cardiol 1982;49:1542-9.

25 Kramer B, Massie B, Topic N. Hemodynamic differences between supine and upright exercise in patients with congestive heart failure. Circulation 1982;66:820-5. 